Portland State University

PDXScholar

Civil and Environmental Engineering Faculty

Publications and Presentations

6-2007

\title{
Modeling Effects of Channel Complexity and Hyporheic Flow on Stream Temperatures
}

\author{
Chris Berger \\ Portland State University \\ Scott A. Wells \\ Portland State University
}

Follow this and additional works at: https://pdxscholar.library.pdx.edu/cengin_fac

Part of the Civil and Environmental Engineering Commons, and the Hydrology Commons Let us know how access to this document benefits you.

\section{Citation Details}

Berger, Chris and Wells, Scott A., "Modeling Effects of Channel Complexity and Hyporheic Flow on Stream Temperatures" (2007). Civil and Environmental Engineering Faculty Publications and Presentations. 141. https://pdxscholar.library.pdx.edu/cengin_fac/141

This Technical Report is brought to you for free and open access. It has been accepted for inclusion in Civil and Environmental Engineering Faculty Publications and Presentations by an authorized administrator of PDXScholar. Please contact us if we can make this document more accessible: pdxscholar@pdx.edu. 


\section{Report as of FY2006 for 2006OR76B: "Modeling Effects of Channel Complexity and Hyporheic Flow on Stream Temperatures"}

\section{Publications}

Project 2006OR76B has resulted in no reported publications as of FY2006.

\section{Report Follows}




\title{
Modeling Effects of Channel Complexity and Hyporheic Flow on Stream Temperatures
}

\author{
胥 Portland State
}

\begin{abstract}
Chris Berger
And

Scott A. Wells

Maseeh College of Engineering and Computer Science

Department of Civil and Environmental Engineering

Portland State University

Portland, Oregon 97201-0751
\end{abstract}

Prepared for Institute for Water and Watersheds

June 2007 


\section{Contents}

MODELING EFFECTS OF CHANNEL COMPLEXITY AND HYPORHEIC FLOW ON STREAM TEMPERATURES ............................................................................................. 3

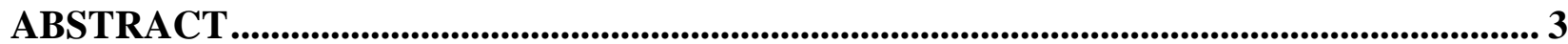

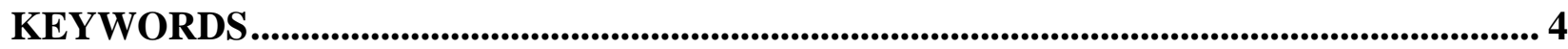

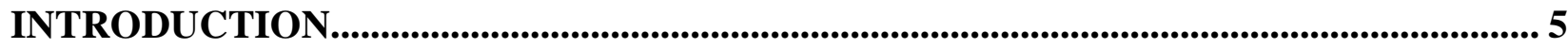

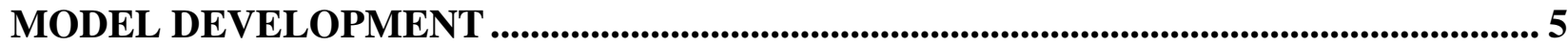

NUMERICAL SOLUTION SCHEME FOR CALCULATING HYPORHEIC HEAD ....... 12

STEADY STATE HEAD TEST ............................................................................................ 14

CONSTITUENT TRANSPORT TEST............................................................................ 18

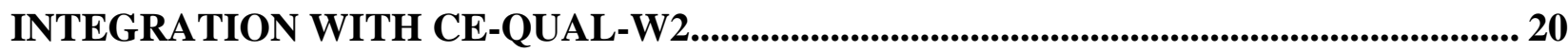

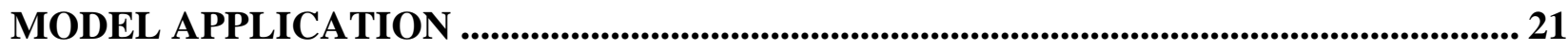

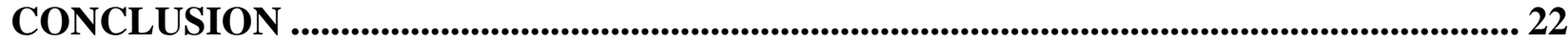

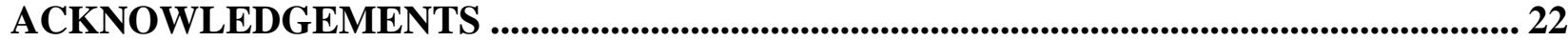

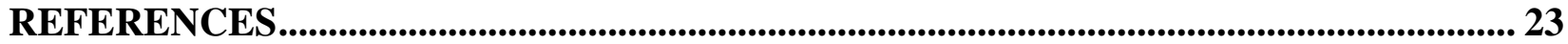

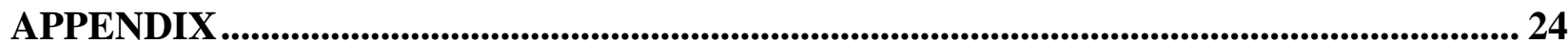




\title{
Modeling Effects of Channel Complexity and Hyporheic Flow on Stream Temperatures
}

Chris J. Berger, Senior Research Associate, Department of Civil and Environmental Engineering, Portland State University, Portland, Oregon

\author{
Scott A. Wells, Professor, Department of Civil and Environmental Engineering, \\ Portland State University, Portland, Oregon
}

Department of Civil and Environmental Engineering, Portland State University, P. O. Box 751, Portland, Oregon 97207-0751, Voice: 503-725-3048, FAX: 503-725-5950, bergerc@cecs.pdx.edu

\begin{abstract}
Stream temperatures are affected by multiple forcing functions, including surface heat exchange (including solar radiation, evaporation, conduction, and net long wave radiation) and hyporheic flows. Each of these forcing functions is directly influenced by the level of channel complexity in the stream channel and riparian shading. The interrelationship between channel complexity, hyporheic flow and stream temperature is highly complex, and efforts to manage for habitat diversity by managing channel complexity could result in unintended consequences on stream temperature. When planning modifications to stream channel complexity, consideration should be given to the effects such moderations could have on stream temperatures.
\end{abstract}

Urbanization has impacted many steams due to the construction of bank protections, levees, vegetation removal, etc. Such activities have eliminated side channels and reduced stream braiding, thereby reducing the overall channel complexity. Hulse et al. (2002) developed maps showing the channel configurations of the Willamette River in Oregon, USA in the years 1850 and 1995. These maps show a significant reduction in channel complexity in the intervening years. More complex stream channels provide greater habitat diversity and thus, are generally more desirable from a wildlife management perspective. Therefore, management of streams for increased channel complexity is gaining in popularity.

Knowing that stream channel complexity has diminished over time, an important question to consider is 'what were stream temperatures before we altered the natural channels?' This is an important issue in determining what natural conditions were and how we have strayed from these so-called 'natural' conditions as a result of channelization, dam building, and changes to the riparian vegetation and deforestation. Current Total Maximum Daily Load's (TMDL) rely on determining a 'natural' condition. In order to develop an understanding of what that is, a hydrodynamic and water quality computer simulation model has been applied to Oregon's Willamette River with several levels of channel complexity and varying rates of hyporheic flows. Adapting the model used to develop TMDL's for temperature in the Willamette River, the effects of present and past channel complexity on water temperatures was determined. The model used to develop the TMDL was the U. S. Army Corps of Engineers dynamic 2-D model CEQUAL-W2, which consists of directly coupled hydrodynamic and water quality transport models 
and simulates parameters such as temperature, algae concentration, dissolved oxygen concentration, $\mathrm{pH}$, nutrient concentrations and residence time. The model also incorporates a dynamic shading algorithm for both vegetative and topographic shading on water bodies.

\section{KEYWORDS}

Temperature Modeling, Hyporheic Flow, CE-QUAL-W2, Willamette River 


\section{INTRODUCTION}

The State of Oregon Department of Environmental Quality (DEQ) developed a river basin temperature model for the Willamette River basin. The study area included the Willamette River and all major tributaries. The model was used by DEQ to set temperature limits on point source dischargers and to evaluate the impact of management strategies on river temperatures to improve fish habitat. Stream temperatures directly influence habitat suitability for salmonids and other aquatic life by directly affecting metabolic rates, food requirements, growth rates, digestion rates, development rates, life-cycle timing, disease and parasite incidence, and predator-prey and competitor interactions (Lewis et al., 2000). The interrelationship between channel complexity, hyporheic flow and stream temperature is highly complex, and efforts to manage for habitat diversity by managing channel complexity could result in unintended consequences on stream temperature. When considering modifications to stream channel complexity, consideration should be given to the affects such moderations could have on stream temperatures.

Urbanization has impacted many streams due to the construction of bank protections, levees, vegetation removal, etc. Such activities have eliminated side channels and reduced stream braiding, thereby reducing the overall channel complexity. Hulse et al. (2002) developed maps showing the channel configurations of the Willamette River in Oregon, USA in the years 1850 and 1995. These maps (Figure 1 and Figure 2) show a significant reduction in channel complexity in the intervening years. More complex stream channels provide greater habitat diversity and thus, are generally more desirable from a wildlife management perspective. Therefore, management of streams for increased channel complexity is gaining in popularity.

The research goal is to investigate the extent which channel complexity and hyporheic flows can influence stream temperatures. Simulations will determine the relative difference observed in stream temperatures between the more- and less-complex channel systems with varying amounts of hyporheic flow and shade. Analysis will also evaluate critical densities and heights of streamside vegetation necessary to provide a net reduction in stream temperatures. From this work an assessment of 'natural' conditions for temperature in this section of the Willamette will be developed and compared to the 'natural' condition of the DEQ TMDL model.

\section{MODEL DEVELOPMENT}

Stream temperatures are influenced by processes that are external to the stream and by processes that occur within the stream system and the associated riparian zone. Most prominent of these forcing functions include incidence of solar radiation, topographic shade, vegetative shade, air temperature, relative humidity, wind speed and direction, precipitation, phreatic flows, and hyporheic flows (Poole \& Berman 2000). Channel complexity is directly related to nearly all of these forcing functions. Broader streams have more surface area and thus have greater exposure to solar radiation. Deeply incised streams and narrow streams are likely to have more shading (on a percentage basis) from streamside vegetation. Stream channels located in deep, sharply cut or narrow valleys, as opposed to broad alluvial valleys, are 
likely to experience more shading from surrounding topographic features. Streams located in deeply cut valleys are likely to have winds directed along the axis of the valley, thus greater wind exposure is possible, while broad alluvial valleys may experience less wind funneling, and thus have less exposure to winds. While riparian vegetation can provide shade, it can also trap cool or warm air in the stream corridor or provide shelter from prevailing winds.

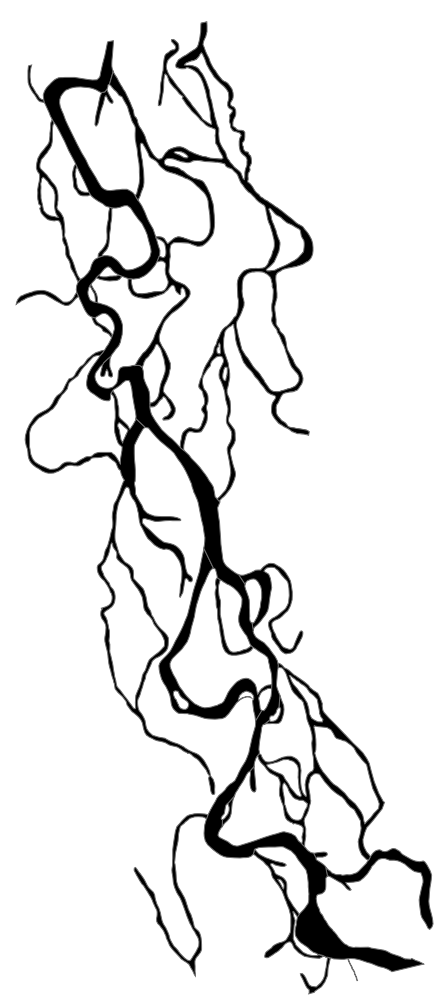

Figure 1. Willamette River channel configuration as it appears to have existed in $\mathbf{1 8 5 0}$. This six-mile reach of the river is located a few miles north of Eugene, Oregon (Hulse et al., 2002)

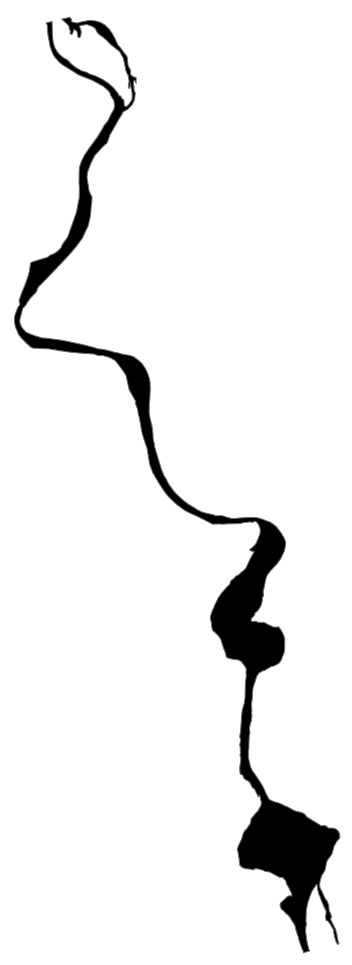

Figure 2. Willamette River channel configuration as it appeared in 1995 . This is the same six-mile river reach shown in Figure 2. Urbanization has resulted in a dramatic reduction in channel complexity (Hulse et al., 2002).

Models developed to predict stream temperatures typically simulate the heat exchange functions given flow, meteorological, and stream channel configurations. CE-QUAL-W2 is a twodimensional, longitudinal/vertical, hydrodynamic and water quality computer simulation model developed by the US Army Corps of Engineers (Cole and Wells 2006). This model includes a compartmentalized heat exchange function based on the following:

$\mathrm{H}_{\mathrm{n}}=\mathrm{H}_{\mathrm{s}}+\mathrm{H}_{\mathrm{a}}+\mathrm{H}_{\mathrm{e}}+\mathrm{H}_{\mathrm{c}}-\left(\mathrm{H}_{\mathrm{sr}}+\mathrm{H}_{\mathrm{ar}}+\mathrm{H}_{\mathrm{br}}\right)$

where $\mathrm{H}_{\mathrm{n}}=$ the net rate of heat exchange across the water surface; $\mathrm{H}_{\mathrm{s}}=$ incident short wave solar radiation; $\mathrm{H}_{\mathrm{a}}=$ incident long wave radiation; $\mathrm{H}_{\mathrm{e}}=$ evaporative heat loss; $\mathrm{H}_{\mathrm{c}}=$ heat conduction; $\mathrm{H}_{\mathrm{sr}}=$ reflected short wave solar radiation; $\mathrm{H}_{\mathrm{ar}}=$ reflected long wave solar radiation; and $\mathrm{H}_{\mathrm{br}}=$ back radiation from the water surface. Each of the above compartments is solved individually to predict stream temperatures throughout the model's domain and over the time period of interest. 
CE-QUAL-W2 simulates the hydrodynamics of the system by simultaneous solution of the continuity and momentum equations. The results of the hydrodynamics are used in the solution of the energy continuity compartment. The hydrodynamic calculations affect the travel time and depth of flow through the river channel and thus can affect heat transfer processes significantly.

The governing equations in CE-QUAL-W2 include the $x$-momentum equation, the continuity equation, the free water surface equation, and the constituent transport equation. The six governing equations were derived from three-dimensional, turbulent and time averaged equations. A discussion of their derivation is supplied in Edinger and Buchak (1978) and Wells (1997). The six unknowns are pressure, $\boldsymbol{F}$; horizontal velocity, $\mathbf{C}$; vertical velocity, $\mathbf{W}$; constituent concentration, $\boldsymbol{q}$; density, $\boldsymbol{\rho}_{\boldsymbol{v}}$; and free water surface elevation, $\boldsymbol{\nu}$ If macrophytes are modeled, porosity $s$ is the ratio of plant volume in a model cell to total wetted cell volume. Conservation of mass is governed by the continuity equation:

$\frac{\partial}{\partial x}(U \phi B)+\frac{\partial}{\partial z}(W \phi B)=q \phi B$

where $\boldsymbol{Z}$ is the channel width and $\boldsymbol{c}$ is the lateral inflow/outflow per unit volume. Assumptions implicit in the equation's derivation include a width-averaged channel and constant fluid density.

Conservation of fluid momentum in the horizontal direction is governed by the $\mathrm{x}$-momentum equation:

$$
\begin{aligned}
& \frac{\partial}{\partial t}(U \phi B)+\frac{\partial}{\partial x}(U U \phi B)+\frac{\partial}{\partial z}(W U \phi B)= \\
& -\frac{\phi B}{\rho_{w}} \frac{\partial p}{\partial x}+\frac{1}{\rho_{w}} \frac{\partial}{\partial x}\left(\phi B \tau_{x x}\right)+\frac{1}{\rho_{w}} \frac{\partial}{\partial z}\left(\phi B \tau_{x z}\right)
\end{aligned}
$$

$\tau_{x .}$ is the turbulent shear stress acting in the $x$-direction on the $x$-face of the control volume and $\tau_{x}$ is the turbulent shear stress acting in the $x$-direction on the $z$-face of the control volume.

The vertical momentum equation simplifies to the hydrostatic equation by assuming that vertical velocities are very low compared to horizontal velocities $(U>C W)$ :

$$
\frac{1}{\rho_{w}} \frac{\partial p}{\partial z}=g
$$

The free water surface equation is obtained by integrating the continuity equation over depth: 
$\frac{\partial}{\partial t}\left(\phi \mathrm{B}_{\eta} \eta\right)=\frac{\partial}{\partial x} \int_{\eta}^{h} U \phi \mathrm{B} d z-\int_{\eta}^{h} q \phi \mathrm{B} d z$

where $\boldsymbol{B}_{\boldsymbol{1}}$ is the surface width, $\boldsymbol{z}$ is the free water surface elevation and $\boldsymbol{Z}$ is the bottom elevation. In CE-QUAL-W2 the free water surface elevation is integrated over all the layers in a segment.

Constituent transport is governed by the constituent transport equation:

$\frac{\partial}{\partial t}(\phi B \Phi)+\frac{\partial}{\partial x}(U \phi B \Phi)+\frac{\partial}{\partial z}(W \phi B \Phi)-\frac{\partial}{\partial x}\left(\phi B D_{x} \frac{\partial \Phi}{\partial x}\right)-\frac{\partial}{\partial z}\left(\phi B D_{z} \frac{\partial \Phi}{\partial z}\right)=$

$q_{\phi} \phi B+S_{K} \phi B$

where $D_{\lambda}$ and $D_{z}$ the longitudinal and vertical temperature and constituent dispersion coefficients, respectively. $\boldsymbol{q}_{4}$ is the lateral inflow of constituent per unit volume and $S_{l}$ is the kinetics source/sink term for constituent concentration.

Water density is governed by the equation of state and is a function of temperature $T_{v}$, total dissolved solids concentration $\Phi_{T D s^{\prime}}$ and suspended solids concentration $\Phi_{s:}$ :

$\rho_{w}=f\left(T_{w}, \Phi_{T D S}, \Phi_{S S}\right)$

An algorithm which simulates hyporheic flow through the alluvial aquifer is being added to the CE-QUAL-W2 model code. The model will be able to capture the transient storage effects of hyporheic flow and the transfer of water across the river bed and banks. A conceptualized hyporheic flow zone is shown in Figure 3. 

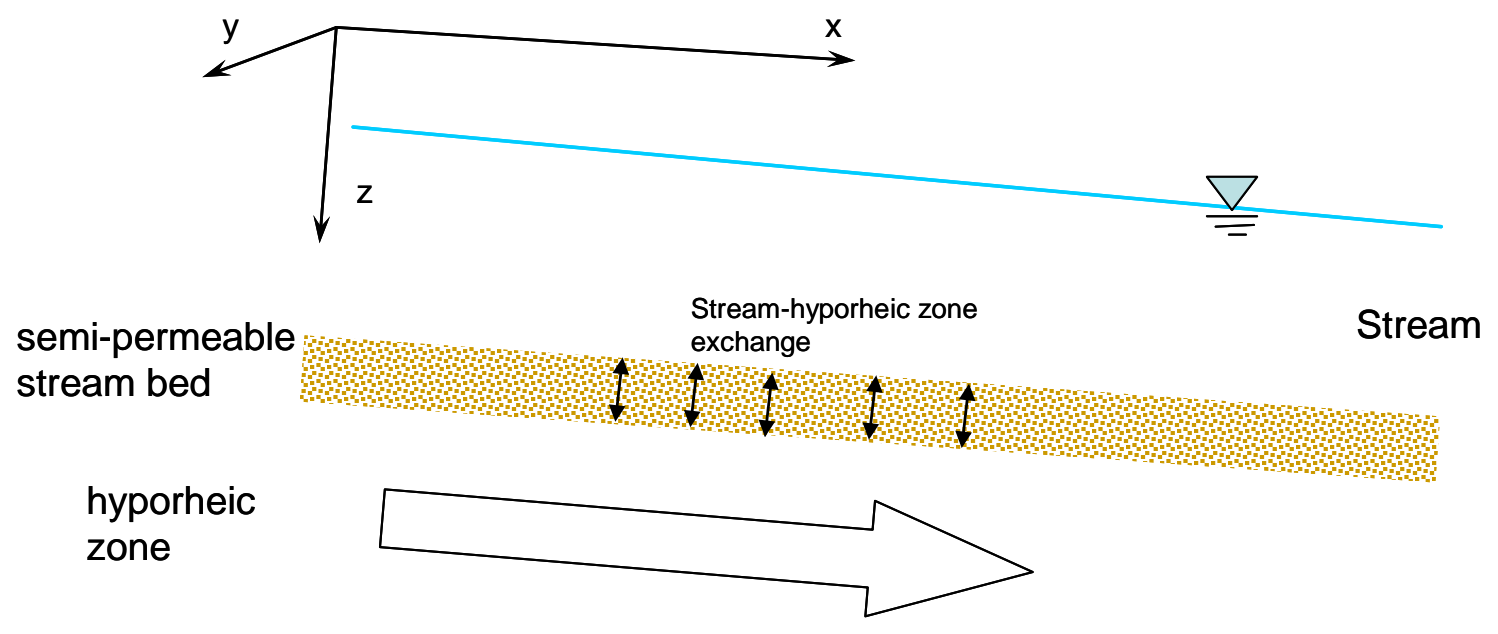

impermeable layer

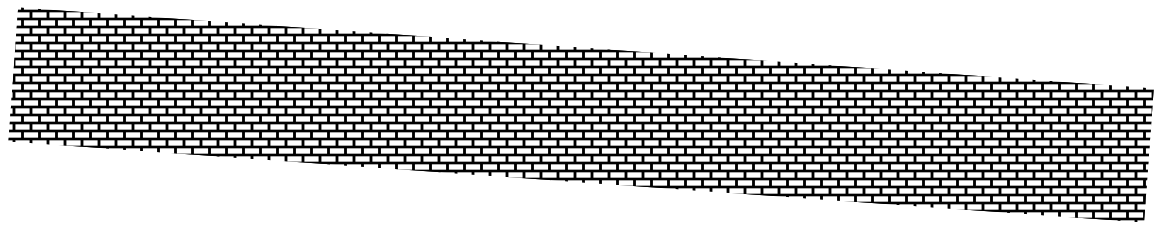

Figure 3. Illustration showing stream, semi-permeable stream bed, hyporheic zone, and the impermeable layer below the hyporheic zone.

Darcy's law is being used to estimate flow through the hyporheic zone. The head $\mathbf{s}_{\mathbf{S}}[\mathrm{L}]$ and hyporheic flow velocity $\bar{c}[\mathrm{~L} / \mathrm{T}]$ are functions of $x, y$, and $z$ such that

$\phi=\phi(x, y, z)$

and

$\vec{q}=\left\{q_{x}, q_{y}, q_{z}\right\}$

Applying Darcy's law and assuming the conductivity $k=k_{x}=k_{y}=k_{z} \quad[\mathrm{~L} / \mathrm{T}]$ is constant,

$\vec{q}=-k \nabla \phi$

or

$\vec{q}=-k\left(\frac{\partial \phi}{\partial x} \vec{i}+\frac{\partial \phi}{\partial y} \vec{j}+\frac{\partial \phi}{\partial z} \vec{k}\right)$

Assuming $\frac{\partial \phi}{\partial y}=\mathrm{C}$ and that $q_{z}=-k \frac{\partial \phi}{\partial z} \approx 0$ within the hyporheic zone, then

$\vec{q}=-k \frac{\partial \phi}{\partial x} \vec{i}$

and 
$q_{x}=-k \frac{\partial \phi}{\partial x}$

The governing equation for hyporheic flow is derived using a control volume of length $\Delta \mathbf{x}$, depth $\boldsymbol{E}$ (thickness of hyporheic zone) and width $\Delta y$ and assuming flow is only in the $x$ direction (Figure 4). The inflow is

$Q_{\text {in }}=-k B \frac{\partial \phi}{\partial x} \Delta y$

Whereas flow rate out is

$Q_{\text {out }}=\left(-k B \frac{\partial \phi}{\partial x}-\Delta x \frac{\partial}{\partial x} k B \frac{\partial \phi}{\partial x}\right) \Delta y$

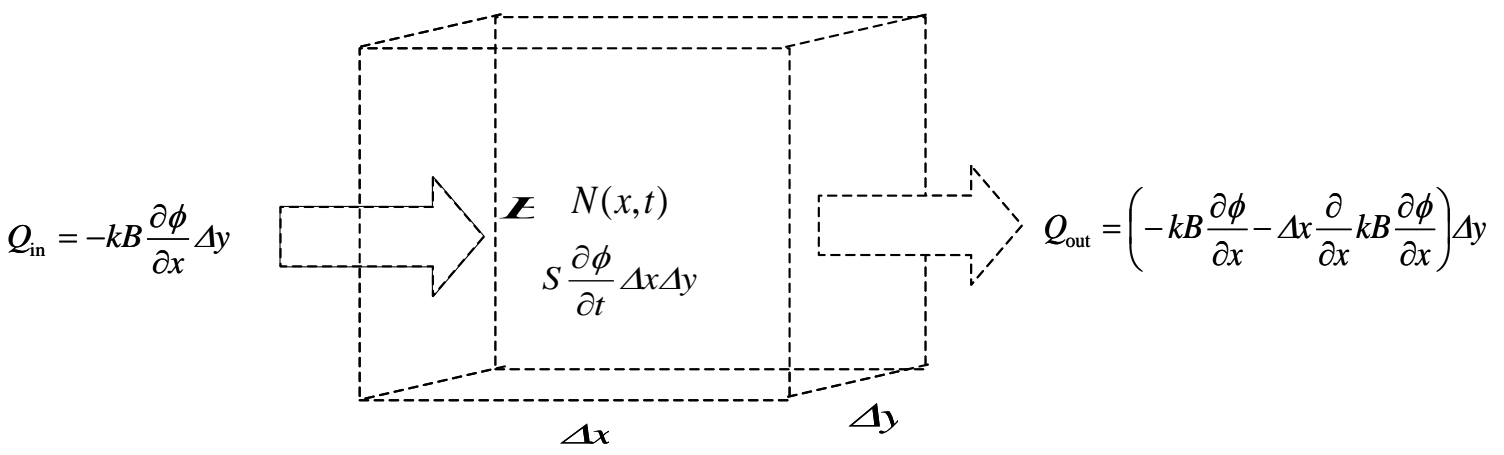

Figure 4. Control volume with length $\Delta x$, depth $Z$ and width $\Delta y$.

A flow balance can be constructed giving

$$
\underbrace{S \frac{\partial \phi}{\partial t} \Delta x \Delta y}_{\substack{\text { changein fluid volume } \\ \text { per unit time }}}=\underbrace{-k B \frac{\partial \phi}{\partial x} \Delta y}_{\text {flow in }}-\underbrace{\left(-k B \frac{\partial \phi}{\partial x}-\Delta x \frac{\partial}{\partial x} k B \frac{\partial \phi}{\partial x}\right)}_{\text {flow out }} \Delta y+\underbrace{N(x, t)}_{\text {sourcessinks }}
$$

where the dimensionless parameter $\leqslant$ is the storativity and $N(x, t)\left[\mathrm{L}^{3} / \mathrm{T}\right]$ is the net flow rate of sources and sinks. Simplifying gives

$S \frac{\partial \phi}{\partial t}=\frac{\partial}{\partial x} k B \frac{\partial \phi}{\partial x}+\frac{N(x, t)}{\Delta x \Delta y}$

Letting $\frac{N(x, t)}{\Delta x \Delta y}=\varepsilon(x, t)$

$S \frac{\partial \phi}{\partial t}=\frac{\partial}{\partial x} k B \frac{\partial \phi}{\partial x}+\varepsilon(x, t)$ 
The source/sink term $\varepsilon(x, t)[\mathrm{L} / \mathrm{T}]$ represents flow across the stream bed between the hyporheic zone and the stream:

$\varepsilon(x, t)=\frac{k^{\prime}}{b^{\prime}}\left(\phi_{\circ}-\phi\right)$

where

$\phi=$ water level in stream [L]

$k^{\prime}=$ conductivity through stream bed $[\mathrm{L} / \mathrm{T}]$

$\boldsymbol{b}^{\prime}=$ thickness of streambed [L]

Substituting for $\varepsilon(x, t)$ gives the following governing equation:

$S \frac{\partial \phi}{\partial t}=\frac{\partial}{\partial x} k B \frac{\partial \phi}{\partial x}+\frac{k^{\prime}}{b^{\prime}}\left(\phi_{\circ}-\phi\right)$

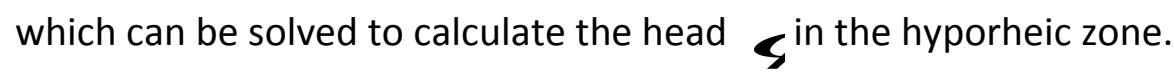

The control volume approach is also used to derive the governing equations for constituent transport. It is assumed that flow and variation in concentration occur only in the $\mathrm{x}$-direction. Given the mass dispersive flux $m_{\lambda}\left[\mathrm{M} / \mathrm{L}^{2}-\mathrm{T}\right]$ the rate of change in mass in the control volume can be expressed as:

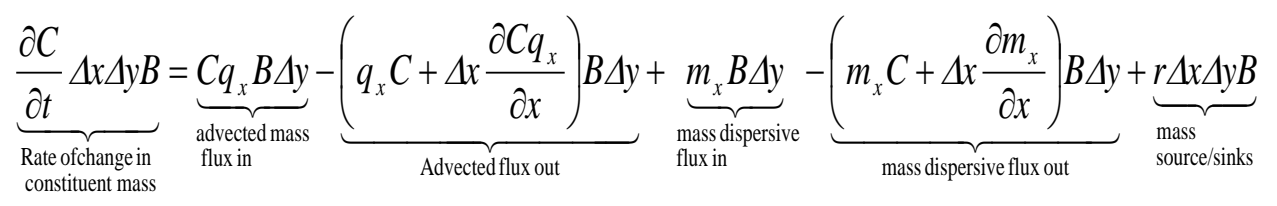

The mass dispersive flux is:

$m_{x}=-D_{x} \frac{\partial c}{\partial x}$

where $D_{\lambda}\left[\mathrm{L}^{2} / \mathrm{T}\right]$ is the coefficient of dispersion. Figure 5 shows the control volume for constituent transport. 


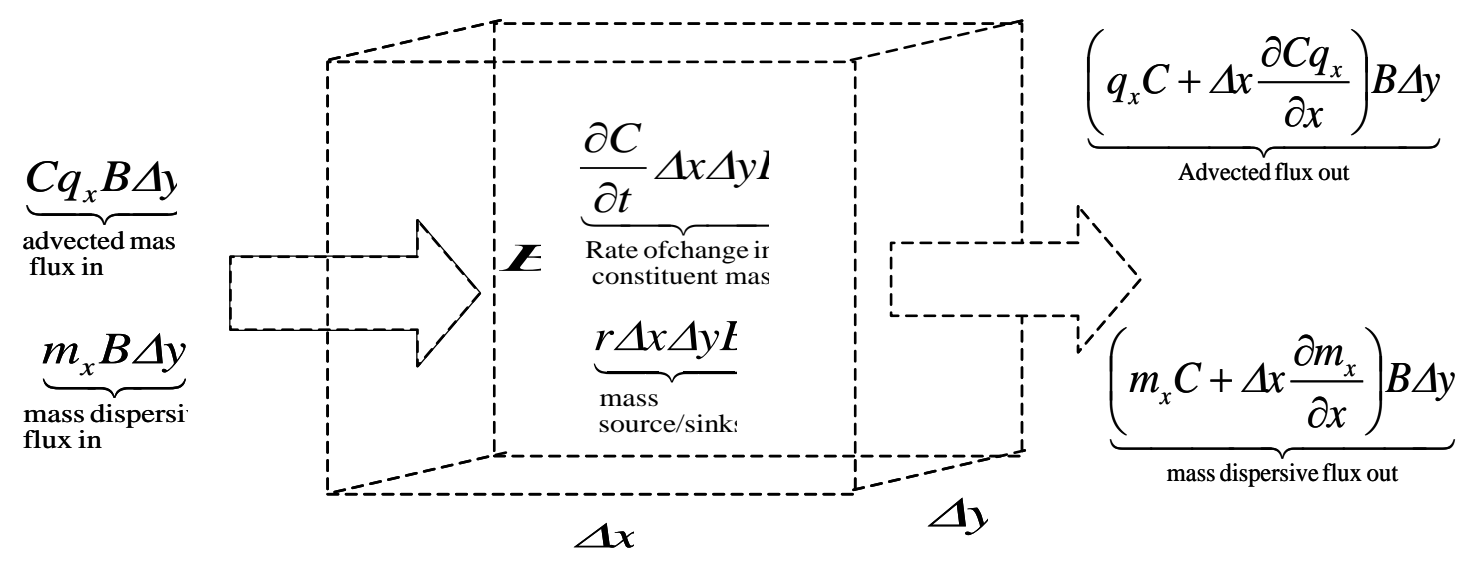

Figure 5. Control volume for constituent transport.

Simplifying and substituting for $m_{\lambda}$ gives

$\frac{\partial C}{\partial t}+\frac{\partial C q_{x}}{\partial x}=\frac{\partial}{\partial x} D_{x} \frac{\partial C}{\partial x}+r$

Constituent transport between the hyporheic zone and the stream is modeled using the source/sink term $r$.

\section{NUMERICAL SOLUTION SCHEME FOR CALCULATING HYPORHEIC HEAD}

The head in the hyporheic zone was calculated using the governing equation

$S \frac{\partial \phi}{\partial t}-\frac{\partial}{\partial x}\left(k B_{T} \frac{\partial \phi}{\partial x}\right)-\frac{k^{\prime}}{b^{\prime}}\left(\phi_{w}-\phi\right)=0$

Where

$\varsigma_{\text {shead [L] }}$

E=storativity

$\boldsymbol{E}=$ width [L]

$\boldsymbol{Z}=$ conductivity $[\mathrm{L} / \mathrm{T}]$

$\phi_{v}=$ water level in stream [L]

$\boldsymbol{k}^{\prime}=$ conductivity through stream bed $[\mathrm{L} / \mathrm{T}]$

$\boldsymbol{b}^{\prime}=$ thickness of streambed $[\mathrm{L}]$

Once the head $\boldsymbol{s}$ is determined, the velocity $\boldsymbol{q}$, can be estimated using

$q_{x}=-k \frac{\partial \phi}{\partial x}$

The head $s$ will be calculated at the center of a model cell. Figure 6 shows a sample grid. 


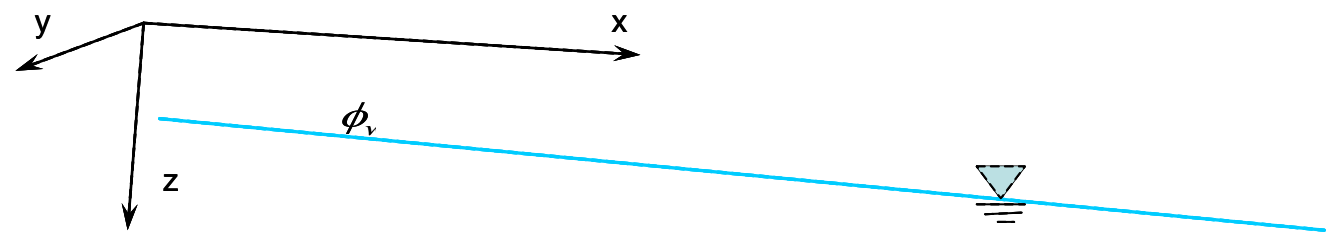

semi-permeable stream bed

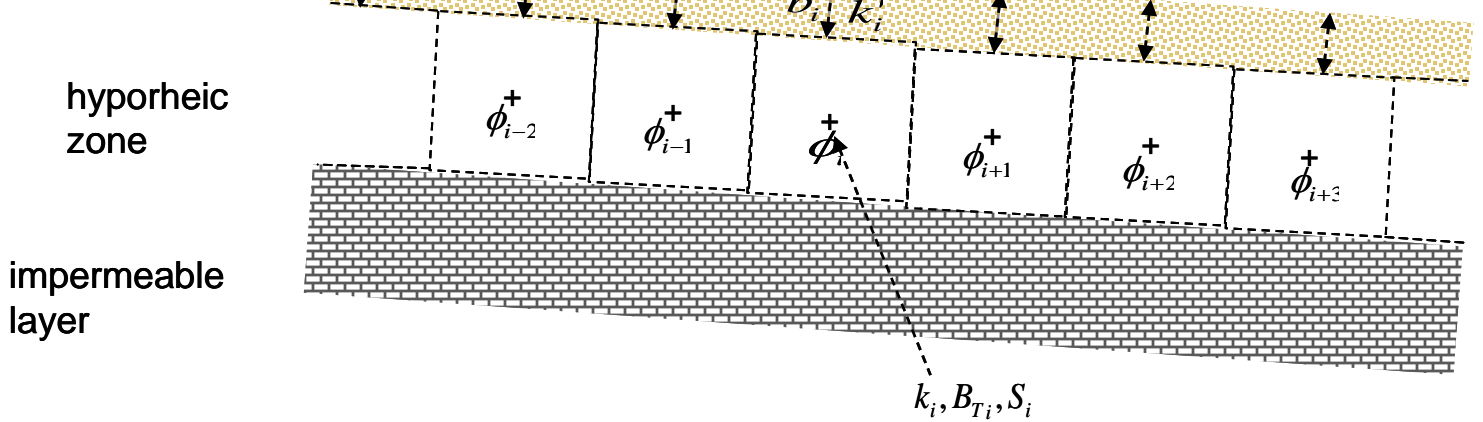

Figure 6. Example grid used for hyporheic zone.

To determine the head in the hyporheic zone, an implicit finite difference scheme was applied where the time derivative was expressed as

$\frac{\partial \phi}{\partial t} \approx \frac{\phi_{i}^{n+1}-\phi_{i}^{n}}{\Delta t}$

and the spatial derivatives were

$\frac{\partial^{2} \phi}{\partial x^{2}} \approx \theta \frac{\phi_{i+1}^{n+1}-2 \phi_{i}^{n+1}+\phi_{i-1}^{n+1}}{\Delta x^{2}}+(1-\theta) \frac{\phi_{i+1}^{n}-2 \phi_{i}^{n}+\phi_{i-1}^{n}}{\Delta x^{2}}$

and

$\frac{\partial \phi}{\partial x} \approx \theta \frac{\phi_{i+1}^{n+1}-\phi_{i-1}^{n+1}}{2 \Delta x}+(1-\theta) \frac{\phi_{i+1}^{n}-\phi_{i-1}^{n}}{2 \Delta x}$

where $C$ is the time-weighting factor. A value of $\theta=0$ indicates a fully implicit scheme, whereas a value of $\theta=1$ is fully explicit. Substituting into the governing equation gives

$\frac{\phi_{i}^{n+1}-\phi_{i}^{n}}{\Delta t}-\frac{\theta}{S_{i} \Delta x}\left(\left.k B_{T}\right|_{i+1 / 2} \frac{\phi_{i+1}^{n+1}-\phi_{i}^{n+1}}{\Delta x}-\left.k B_{T}\right|_{i-1 / 2} \frac{\phi_{i}^{n+1}-\phi_{i-1}^{n+1}}{\Delta x}\right)-$

$\frac{(1-\theta)}{S_{i} \Delta x}\left(\left.k B_{T}\right|_{i+1 / 2} \frac{\phi_{i+1}^{n}-\phi_{i}^{n}}{\Delta x}-\left.k B_{T}\right|_{i-1 / 2} \frac{\phi_{i}^{n}-\phi_{i-1}^{n}}{\Delta x}\right)+\theta \frac{k_{i}^{\prime}}{S_{i} b_{i}^{\prime}} \phi_{i}^{n+1}+(1-\theta) \frac{k_{i}^{\prime}}{S_{i} b_{i}^{\prime}} \phi_{i}^{n}-\frac{k_{i}^{\prime}}{S_{i} b_{i}^{\prime}} \phi_{w}=0$

And rearranging results in 


$$
\begin{aligned}
& \frac{\theta}{S_{i} \Delta x^{2}}\left(-\left.k B_{T}\right|_{i-1 / 2}\right) \phi_{i-1}^{n+1}+\left(\frac{1}{\Delta t}+\theta \frac{\left.k B_{T}\right|_{i-1 / 2}}{S_{i} \Delta x^{2}}+\theta \frac{\left.k B_{T}\right|_{i+1 / 2}}{S_{i} \Delta x^{2}}+\theta \frac{k_{i}^{\prime}}{S_{i} b_{i}^{\prime}}\right) \phi_{i}^{n+1} \\
& +\frac{\theta}{S_{i} \Delta x^{2}}\left(-\left.k B_{T}\right|_{i+1 / 2}\right) \phi_{i+1}^{n+1}=\left.\left(\frac{1-\theta}{S_{i} \Delta x^{2}}\right) k B_{T}\right|_{i-1 / 2} \phi_{i-1}^{n} \\
& +\left(\frac{1}{\Delta t}-(1-\theta) \frac{k_{i}^{\prime}}{S_{i} b_{i}^{\prime}}-(1-\theta) \frac{1}{S_{i} \Delta x^{2}}\left(\left.k B_{T}\right|_{i+1 / 2}+\left.k B_{T}\right|_{i-1 / 2}\right)\right) \phi_{i}^{n}+\left.\left(\frac{1-\theta}{S_{i} \Delta x^{2}}\right) k B_{T}\right|_{i+1 / 2} \phi_{i+1}^{n}+\frac{k_{i}^{\prime}}{S_{i} b_{i}^{\prime}} \phi_{w} \\
& \text { or } \\
& -\theta \frac{\left.k B_{T}\right|_{i-1 / 2}}{S_{i} \Delta x^{2}} \phi_{i-1}^{n+1}+\left(\frac{1}{\Delta t}+\theta \frac{\left.k B_{T}\right|_{i-1 / 2}}{S_{i} \Delta x^{2}}+\theta \frac{\left.k B_{T}\right|_{i+1 / 2}}{S_{i} \Delta x^{2}}+\theta \frac{k_{i}^{\prime}}{S_{i} b_{i}^{\prime}}\right) \phi_{i}^{n+1} \\
& -\theta \frac{\left.k B_{T}\right|_{i+1 / 2}}{S_{i} \Delta x^{2}} \phi_{i+1}^{n+1}=(1-\theta) \frac{\left.k B_{T}\right|_{i-1 / 2}}{S_{i} \Delta x^{2}} \phi_{i-1}^{n}+\left(\frac{1}{\Delta t}-(1-\theta) \frac{k_{i}^{\prime}}{S_{i} b_{i}^{\prime}}-(1-\theta)\left(\frac{\left.k B_{T}\right|_{i+1 / 2}}{S_{i} \Delta x^{2}}+\frac{\left.k B_{T}\right|_{i-1 / 2}}{S_{i} \Delta x^{2}}\right) \phi_{i}^{n}+\right. \\
& (1-\theta) \frac{\left.k B_{T}\right|_{i+1 / 2}}{S_{i} \Delta x^{2}} \phi_{i+1}^{n}+\frac{k_{i}^{\prime}}{S_{i} b_{i}^{\prime}} \phi_{w}
\end{aligned}
$$

This equation was solved using a tri-diagonal matrix solver pre-existing in the CE-QUAL-W2 source code to determine the head $s$ in the hyporheic flow zone.

\section{STEADY STATE HEAD TEST}

The hyporheic flow module was initially tested separately from CE-QUAL-W2 by simulating steady state conditions with fixed head boundary conditions and leakage between an aquifer and a overlying body of water (Figure 7). The governing equation for the steady state system is

$\frac{\partial}{\partial x}\left(k B_{T} \frac{\partial \phi}{\partial x}\right)+\frac{k^{\prime}}{b^{\prime}}\left(\phi_{w}-\phi\right)=0$

since $\frac{\partial \phi}{\partial t}=\mathrm{C}$. If $k B_{T}=0$ the governing equation simplifies to

$k B_{T} \frac{\partial^{2} \phi}{\partial x^{2}}+\frac{k^{\prime}}{b^{\prime}}\left(\phi_{w}-\phi\right)=0$

with fixed head boundary conditions $\phi(x=0)=\phi_{\circ}$ and $\phi(x=L)=\phi_{L} \quad$ where $\boldsymbol{Z}$ is the distance to the downstream boundary condition. To solve, the governing equation can be rewrote 
$k B_{T} \frac{\partial^{2}\left(\phi-\phi_{w}\right)}{\partial x^{2}}-\frac{k^{\prime}}{b^{\prime}}\left(\phi-\phi_{w}\right)=0$

and letting $f(x)=\phi(x)-\phi_{w}$ such that

$k B_{T} \frac{\partial^{2} f}{\partial x^{2}}-\frac{k^{\prime}}{b^{\prime}} f=0$

where $f(x=0)=\phi_{\circ}-\phi_{w}$ and $\phi(x=L)=\phi_{L}-\phi_{w}$. If $\lambda=\sqrt{\frac{k^{\prime}}{k B_{T} b^{\prime}}}$ the governing equation can be written

$\frac{\partial^{2} f}{\partial x^{2}}-\lambda f=0$

The solution for has the form

$$
f(x)=c_{1} e^{-\lambda x}+c_{2} e^{\lambda x}
$$

where $C$ and $\boldsymbol{C}_{z}$ are constants. At $x=0$, the boundary condition is

$$
f(0)=\phi_{\circ}-\phi_{w}=c_{1}+c_{2}
$$

giving $c_{2}=\phi_{\circ}-\phi_{w}-c_{1}$.

At $x=L$, the boundary condition is

$$
f(L)=\phi_{L}-\phi_{w}=c_{1} e^{-\lambda L}+c_{2} e^{\lambda L}=c_{1} e^{-\lambda L}+\left(\phi_{o}-\phi_{w}-c_{1}\right) e^{\lambda L}
$$

resulting in

$c_{1}=\frac{\phi_{L}+\phi_{w}\left(e^{\lambda L}-1\right)-e^{\lambda L} \phi_{\circ}}{e^{-\lambda L}-e^{\lambda L}}$

and

$c_{2}=\phi_{\circ}-\phi_{w}-\frac{\phi_{L}+\phi_{w}\left(e^{\lambda L}-1\right)-e^{\lambda L} \phi_{\circ}}{e^{-\lambda L}-e^{\lambda L}}$

The solution for $\phi(x)$ is thus

$\phi(x)=c_{1} e^{-\lambda x}+c_{2} e^{\lambda x}+\phi_{w}$ 


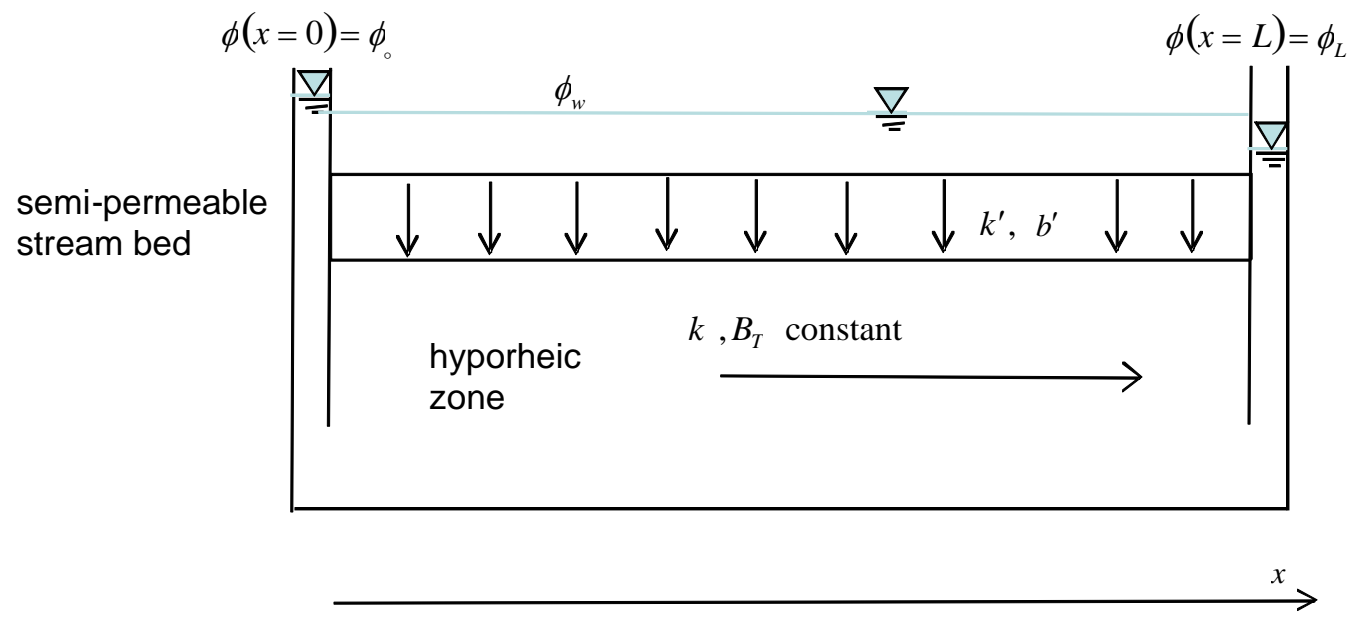

Figure 7. Hyporheic flow test case where condtions are steady-state, the upstream and downstream head boundary conditions are fixed, and leakage occurs between aquifer and overlying water body.

Five simulations were conducted with varying parameter values.

Table 1 lists the coefficients used in the different test simulations. The model grid consisted of 12 model segments, each $10 \mathrm{~m}$ long $(\Delta x=10 \mathrm{~m})$. The storativity, hyporheic zone conductivity, stream bed conductivity, and stream bed thickness were assumed to be constant. The comparisons between the analytical solution and model predictions for head were shown in Figure 8. Error statistics, including mean error, absolute mean error, and root mean square error were listed in Table 2. The average absolute mean error for all the steady-state test cases was $0.003 \mathrm{~m}$. Source code used for the steady state head test is shown in Appendix.

Table 1. Coefficient values used model test of steady-state conditions with leakage.

\begin{tabular}{l|llllllll}
\hline $\begin{array}{l}\text { Test } \\
\#\end{array}$ & $\begin{array}{l}\text { Upstream } \\
\text { Head }(\mathrm{m}) \\
\boldsymbol{\phi}_{\mathrm{c}}\end{array}$ & $\begin{array}{l}\text { Downstream } \\
\text { Head }(\mathrm{m})\end{array}$ & $\begin{array}{l}\text { Overlying } \\
\text { Head }(\mathrm{m}) \\
\boldsymbol{\phi}_{\boldsymbol{I}}\end{array}$ & $\begin{array}{l}\text { Stora- } \\
\text { tivity } \\
\mathbf{\boldsymbol { c }}\end{array}$ & $\begin{array}{l}\text { Hyporheic } \\
\text { zone } \\
\text { cond. } \\
(\mathrm{m} / \mathrm{s})\end{array}$ & $\begin{array}{l}\text { Hyorheic } \\
\text { zone } \\
\text { thick. }(\mathrm{m})\end{array}$ & $\begin{array}{l}\text { Stream } \\
\text { bed } \\
\text { cond. } \\
(\mathrm{m} / \mathrm{s})\end{array}$ & $\begin{array}{l}\text { Stream } \\
\text { bed } \\
\text { thick. } \\
(\mathrm{m})\end{array}$ \\
\hline 1 & 3.0 & 2.5 & 2.75 & 0.0001 & 0.004 & 10.0 & 0.00004 & 0.2 \\
2 & 4.0 & 3.0 & 3.9 & 0.0002 & 0.001 & 1.0 & 0.00001 & 0.4 \\
3 & 3.0 & 4.0 & 3.5 & 0.0001 & 0.004 & 5.0 & 0.00002 & 0.4 \\
4 & 2.0 & 1.0 & 2.5 & 0.0001 & 0.006 & 5.0 & 0.0004 & 0.3 \\
5 & 3.0 & 1.0 & 2.0 & 0.0001 & 0.008 & 10.0 & 0.00001 & 2.0 \\
\hline
\end{tabular}


Figure 8. Comparison of model predictions with analytical solution for steady state test cases with leakage to hyporheic zone.

Table 2. Error statistics of model predictions with analytical solutions for steady state test cases with leakage to hyporheic zone.

\begin{tabular}{l|lll}
\hline Test \# & Mean Error $(m)$ & $\begin{array}{l}\text { Absolute } \\
(m)\end{array}$ & $\begin{array}{l}\text { Mean } \\
(m)\end{array}$ \\
\hline 1 & 0.000 & 0.001 & 0.001 \\
2 & 0.003 & 0.004 & 0.008 \\
3 & 0.000 & 0.001 & 0.001 \\
4 & 0.009 & 0.009 & 0.018 \\
5 & 0.000 & 0.000 & 0.000 \\
\hline Average & 0.002 & 0.003 & 0.006 \\
\hline
\end{tabular}




\section{CONSTITUENT TRANSPORT TEST}

Another test case was used to compare model predictions of constituent transport in the hyporheic zone with an analytical solution. Model predictions were made using a CE-QUAL-W2 test code which included the hyporheic flow module. Constituent transport in the hyporheic zone is modeled using the following governing equation:

$\frac{\partial C}{\partial t}+\frac{\partial C q_{x}}{\partial x}=\frac{\partial}{\partial x} D_{x} \frac{\partial C}{\partial x}+r$

The solution of to the constituent transport equation was determined using an advectivediffusion solution scheme pre-existing in CE-QUAL-W2. For the test case transport across the stream bed was assumed to be zero $(r=0)$. The horizontal velocity $\boldsymbol{q}$, and dispersion $D_{\lambda}$ were assumed to be constant giving

$\frac{\partial C}{\partial t}+q_{x} \frac{\partial C}{\partial x}=D_{x} \frac{\partial^{2} C}{\partial^{2} x}$

The initial concentration in the hyporheic zone was set to zero and the concentration at the left hand boundary $x=0$ was $C_{c}$. The initial condition and boundary conditions were thus

$C(0, t)=C_{\circ}, \quad 0<t<\infty$

$C(x, 0)=0, \quad 0<x<\infty$

The analytical solution to this equation is

$C(x, t)=\frac{C_{\circ}}{2}\left[\operatorname{erfc}\left(\frac{x-q_{x} t}{\sqrt{4 D t}}\right)+\operatorname{erfc}\left(\frac{x+q_{x} t}{\sqrt{4 D t}}\right) \exp \left(\frac{q_{x} x}{D}\right)\right]$

The test case was diagrammed in Figure 9. With increasing time the constituent front travels to the right due to advection while also spreading out because of dispersion. The coefficient parameters used in the test cases were listed in Table 3. The concentration at the left hand boundary $C_{c}$ was assumed to be $100 \mathrm{mg} / \mathrm{l}$. The model grid consisted of 100 segments, each 10 $\mathrm{m}$ long $(\Delta x=100 \mathrm{~m})$. Model predictions are compared with the analytical solution in Figure 10. The mean error, absolute mean error, and root mean square error of the test cases were listed in Table 4. 


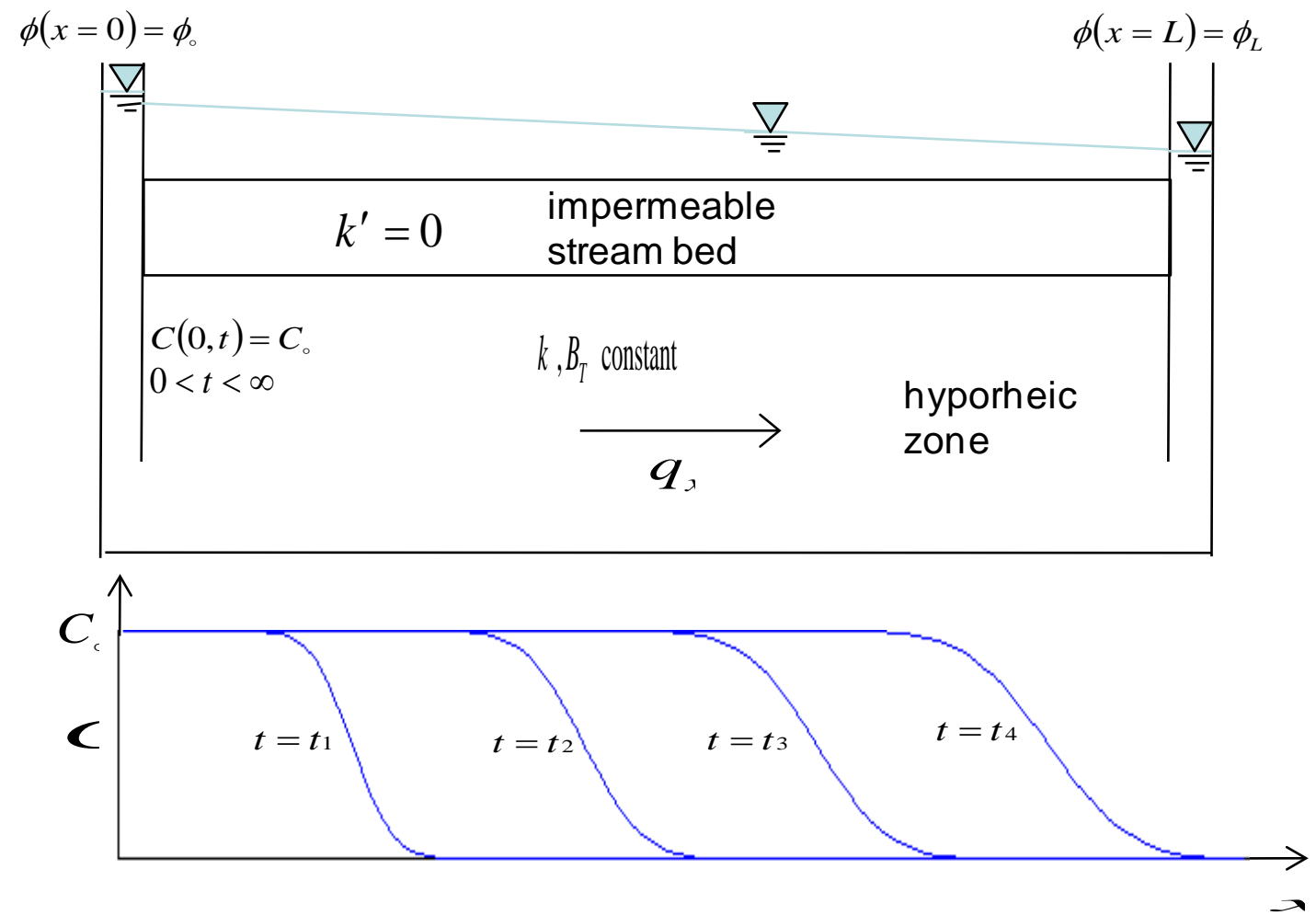

Figure 9. The constituent transport test case where a constituent of concentration $C_{\text {c }}$ is released continuously at the location $x=0$ starting at time $t=0$

Table 3. Coefficient values used model constituent transport test.

\begin{tabular}{|c|c|c|c|c|c|c|c|c|}
\hline $\begin{array}{l}\text { Test } \\
\#\end{array}$ & $\begin{array}{l}\text { Upstream } \\
\text { Head (m) } \\
\phi_{c}\end{array}$ & $\begin{array}{l}\text { Downstream } \\
\text { Head }(m) \\
\phi_{I}\end{array}$ & $\begin{array}{l}\text { Dispersion } \\
\left(\mathrm{m}^{2} / \mathrm{s}\right) \\
D_{\lambda}\end{array}$ & $\begin{array}{l}\text { Stora- } \\
\text { tivity } \\
\leq\end{array}$ & $\begin{array}{l}\text { Hyporheic } \\
\text { zone } \\
\text { cond. } \\
(\mathrm{m} / \mathrm{s}) \\
7\end{array}$ & $\begin{array}{l}\text { Hyorheic } \\
\text { zone } \\
\text { thick. (m) } \\
\boldsymbol{B}_{\mathbf{7}}\end{array}$ & $\begin{array}{l}\text { Stream } \\
\text { bed } \\
\text { cond. } \\
(\mathrm{m} / \mathrm{s}) \\
\boldsymbol{k}^{\prime}\end{array}$ & $\begin{array}{l}\text { Stream } \\
\text { bed } \\
\text { thick. } \\
\text { (m) } \\
\boldsymbol{b}^{\prime}\end{array}$ \\
\hline 6 & 3.0 & 2.5 & 0.02 & 0.0001 & 0.020 & 10.0 & 0.0 & 0.2 \\
\hline 7 & 3.0 & 2.5 & 0.001 & 0.0001 & 0.100 & 1.0 & 0.0 & 0.2 \\
\hline 8 & 3.0 & 2.5 & 0.020 & 0.0001 & 0.020 & 5.0 & 0.0 & 0.2 \\
\hline
\end{tabular}

Table 4. Error statistics of model predictions with analytical solutions for constituent transport test.

\begin{tabular}{l|llll}
\hline Test \# & Mean Error $(\mathrm{mg} / \mathrm{l})$ & $\begin{array}{l}\text { Absolute } \\
\text { Error }(\mathrm{mg} / \mathrm{l})\end{array}$ & Mean & $\begin{array}{l}\text { Root Mean } \\
\text { Error }(\mathrm{mg} / \mathrm{l})\end{array}$ \\
\hline 6 & -2.0 & 2.0 & 3.3 & \\
7 & -0.2 & 0.2 & 0.6 & \\
8 & -1.0 & 1.0 & 1.8 \\
\hline Average & -1.1 & 1.1 & 1.9 \\
\hline
\end{tabular}


Figure 10. Comparisons of model predictions with analytical solution for constituent transport test cases.

\section{INTEGRATION WITH CE-QUAL-W2}

A specialized input file was created to input hyporheic coefficients. Table 1 lists the coefficients in the input file "hyporheic.npt".

Table 5. List of coefficients used in hyporheic.npt input file.

\begin{tabular}{l|cl}
\hline Variable Name & Equation Variable & Description \\
\hline THETAH & - & Time weighting factor. $\theta=0$ indicates a \\
& & fully implicit scheme, whereas a value of \\
& & $\theta=1$ is fully explicit \\
THI & - & Initial temperature in hyporheic zone \\
& & (Celsius) \\
UHH & - & Upstream branch boundary condition. \\
& & UHH=0 for no-flux boundary, UHH=-1 for \\
DHH & - & head boundary \\
& & Downstream branch boundary condition. \\
& & DHH=0 for no-flux boundary, DHH=-1 for \\
\hline
\end{tabular}




\begin{tabular}{l|cl}
\hline Variable Name & Equation Variable & Description \\
\hline & \multicolumn{2}{c}{ head boundary } \\
STOR & $\boldsymbol{Z}$ & Storativity $(-)$ \\
KC & $\boldsymbol{B}_{\boldsymbol{t}}$ & Hyporheic zone conductivity $(\mathrm{m} / \mathrm{s})$ \\
BT & $\Delta \boldsymbol{y}$ & Hyorheic zone thickness $(\mathrm{m})$ \\
WHP & $\boldsymbol{k}^{\prime}$ & Stream bed width $(\mathrm{m})$ \\
KP & $\boldsymbol{b}^{\prime}$ & Stream bed conductivity $(\mathrm{m} / \mathrm{s})$ \\
BP & $\boldsymbol{D}_{\lambda}$ & Stream bed thickness $(\mathrm{m})$ \\
DXH & Dispersion in groundwater $\left(\mathrm{m}^{2} / \mathrm{s}\right)$ \\
\hline
\end{tabular}

An example file is shown below. The columns are eight spaces wide. This example file corresponds to a model consisting of a single branch, with 20 segments.

hyporheic input file: hyporheic.npt

\begin{tabular}{|c|c|c|c|c|c|c|c|}
\hline & $\begin{array}{r}\text { THETAH } \\
0.55\end{array}$ & $\begin{array}{r}\text { THI } \\
12.0\end{array}$ & & & & & \\
\hline br1 & $\begin{array}{r}\mathrm{UHH} \\
-1\end{array}$ & $\begin{array}{r}\text { DHH } \\
\odot\end{array}$ & & & & & \\
\hline SEG & STOR & KC & BT & WHP & KP & $\mathrm{BP}$ & DXH \\
\hline 1 & $\odot .0001$ & $\odot .500$ & 2.0 & 15.0 & $\odot .100 \odot$ & 0.2 & $\odot .0 \odot 1$ \\
\hline 2 & 0.0001 & 0.500 & 2.0 & 15.0 & $\odot .1000$ & 0.2 & $\odot .001$ \\
\hline 3 & $\odot .0001$ & $\odot .500$ & 2.0 & 15.0 & $\odot .100 \odot$ & 0.2 & $\odot .0 \odot 1$ \\
\hline 4 & $\odot .0001$ & 0.500 & 2.0 & 15.0 & 0.1000 & 0.2 & 0.001 \\
\hline 5 & $\odot .0001$ & 0.500 & 2.0 & 15.0 & $\odot .1000$ & 0.2 & $\odot .001$ \\
\hline 6 & $\odot .0001$ & 0.500 & 2.0 & 15.0 & $\odot .1000$ & 0.2 & $\odot .001$ \\
\hline 7 & $\odot .0001$ & $\odot .500$ & 2.0 & 15.0 & $\odot .1000$ & 0.2 & $\odot .001$ \\
\hline 8 & $\odot .00 \odot 1$ & 0.500 & 2.0 & 15.0 & $\odot .1000$ & 0.2 & $\odot .001$ \\
\hline 9 & $\odot .0001$ & 0.500 & 2.0 & 15.0 & $\odot .1000$ & 0.2 & $\odot .001$ \\
\hline 10 & $\odot .0 \odot \odot 1$ & $\odot .500$ & 2.0 & 15.0 & $\odot .10 \odot \odot$ & 0.2 & $\odot .0 \odot 1$ \\
\hline 11 & $\odot .0001$ & 0.500 & 2.0 & 15.0 & $\odot .100 \odot$ & 0.2 & $\odot .001$ \\
\hline 12 & 0.0001 & 0.500 & 2.0 & 15.0 & $\odot .1000$ & 0.2 & $\odot .001$ \\
\hline 13 & $\odot .0001$ & 0.500 & 2.0 & 15.0 & $\odot .1000$ & 0.2 & $\odot .001$ \\
\hline 14 & $\odot .0001$ & 0.500 & 2.0 & 15.0 & $\odot .1000$ & 0.2 & $\odot .001$ \\
\hline 15 & $\odot .00 \odot 1$ & 0.500 & 2.0 & 15.0 & $\odot .10 \odot \odot$ & 0.2 & $\odot .001$ \\
\hline 16 & $\odot .0 \odot \odot 1$ & 0.500 & 2.0 & 15.0 & $\odot .1000$ & 0.2 & $\odot .001$ \\
\hline 17 & $\odot .00 \odot 1$ & 0.500 & 2.0 & 15.0 & $\odot .10 \odot \odot$ & 0.2 & $\odot .0 \odot 1$ \\
\hline 18 & $\odot .00 \odot 1$ & 0.500 & 2.0 & 15.0 & $\odot .1000$ & 0.2 & $\odot .001$ \\
\hline 19 & $\odot .0 \odot \odot 1$ & $\odot .500$ & 2.0 & 15.0 & $\odot .10 \odot \odot$ & 0.2 & $\odot .0 \odot 1$ \\
\hline 20 & ๑ . ०००1 & 0.500 & 2.0 & 15.0 & 0.1000 & 0.2 & $\odot .001$ \\
\hline
\end{tabular}

\section{MODEL APPLICATION}

Initially, the CE-QUAL-W2 model is being applied to an idealized riverine system consisting of a single main channel and then to the same idealized system, but with the addition of side channels. Assumptions used in the model development, for both systems, includes 15-meter tall dense streamside vegetation, diurnal air temperature fluctuations $\left(7^{\circ} \mathrm{C}\right.$ to $\left.21^{\circ} \mathrm{C}\right)$ based on current meteorological data, constant flow rates and inflow stream temperatures, $44^{\circ}$ north 
latitude, no wind, a domain length of one mile, and with and without hyporheic flows. Also, changes in channel geometry is being explored in the main channel and the side channels. The results of the two models will be compared to evaluate differences in predicted temperature regimes between these two idealized systems.

The CE-QUAL-W2 model is being developed for the two Willamette River channel configurations shown in Figure 1 and Figure 2. The temperature regimes predicted for the two channel configurations are being compared. A sensitivity analysis is being performed to determine the dominant forcing functions affecting stream temperatures and evaluate critical levels for these forcing functions.

\section{CONCLUSION}

A model has been developed for simulating hyporheic flow in rivers. The hyporheic flow model is one-dimensional and based on Darcy's groundwater flow equation. Flow exchange between the stream and hyporheic zone is simulated across a semi-permeable stream bed. Constituent transport in the hyporheic zone is being modeled using the one-dimensional advective-diffusion equation. The hyporheic flow model has been coupled to the hydrodynamic and water quality model CE-QUAL-W2 and has been tested. The hyporheic flow model has been shown to reproduce analytical solutions. The combined impact of multiple stream channels and hyporheic flow will be evaluated. It will also be used to model to temperatures in the Willamette River, Oregon. Past and present channel configurations are being simulated in order to determine the impact of channelization on stream temperatures. Model predictions will be compared with data to validate the model's suitability for simulating present conditions.

When the project is complete a tool will be available that can model flow and constituent transport in the hyporheic zone of streams. This hyporheic flow feature will be part of future versions of CE-QUAL-W2. The prediction of pre-development or natural condition stream temperatures often necessary in TMDL studies will be made easier with a tool simulating the combined effect of hyporheic flow and channel complexity.

\section{ACKNOWLEDGEMENTS}

This research has been funded by the Institute for Water and Watersheds at Oregon State University through the United State Geological Survey mini-grant program. 


\section{REFERENCES}

Cole, T. M. \& Wells, S. A. 2006. CE-QUAL-W2: A two-dimensional, laterally averaged, hydrodynamic and water quality model, version 3.5. Instruction Report EL-06-1. U.S. Army Engineering and Research Development Center, Vicksburg, MS.

Edinger, J. E. and Buchak, E. M. (1978). "Numerical hydrodynamics of estuaries." Estuarine and Wetland Processes with Special Emphasis on Modeling, edited by P. Hamilton and K. B. MacDonald, Plenum Press, NY, 115-146.

Hulse, D., Gregory, S. and Baker, J. 2002. Willamette River basin planning atlas: Trajectories of environmental and ecological change. Oregon State University Press. Corvallis: USA

Lewis, T., D. McCanne, A. Webb, J. Krieter and W. Conroy. 2000. Regional assessment of stream temperatures across Northern California and their relationship to various landscape-level and site-specific attributes. Forest Science Project, Humboldt State University Foundation. Arcata: USA

Poole, G.C. \& Berman, C.H. 2000. Pathways of human influence on water temperature dynamics in stream channels. U.S. Environmental Protection Agency, Region 10. Seattle: USA.

Wells, S. A. (1997). "Theoretical basis of the CE-QUAL-W2 river basin model." Technical Report Environmental and Water Resource, Number 6, 1997 (EWR-6-97), Department of Civil Engineering, Portland State University, Portland, Oregon. 


\section{Appendix}

The code used in the CE-QUAL-W2 model is written in Fortran 90/95. This appendix contains the test codes used to verify the hyporehic flow algorithms in the CE-QUAL-W2 model.

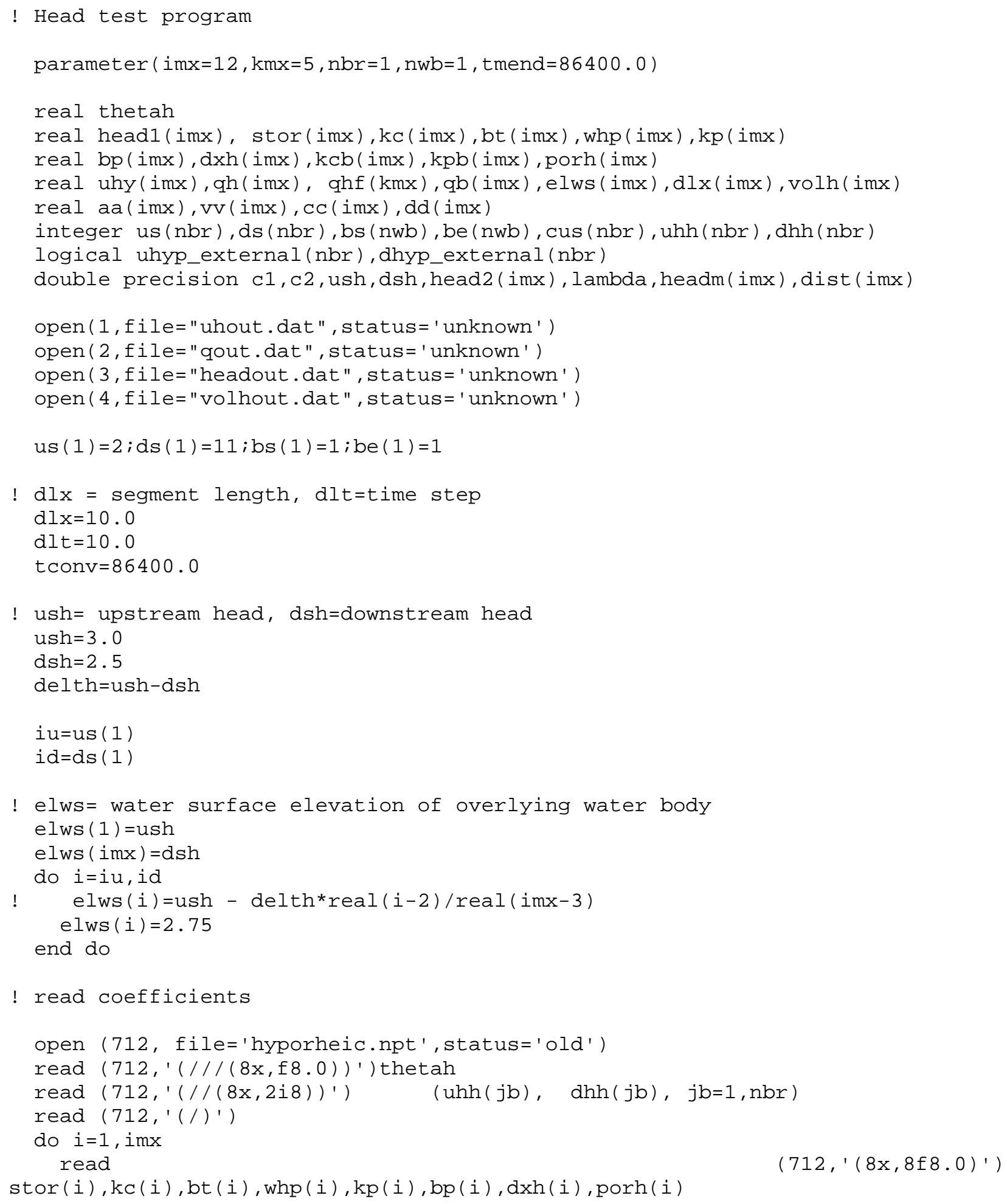




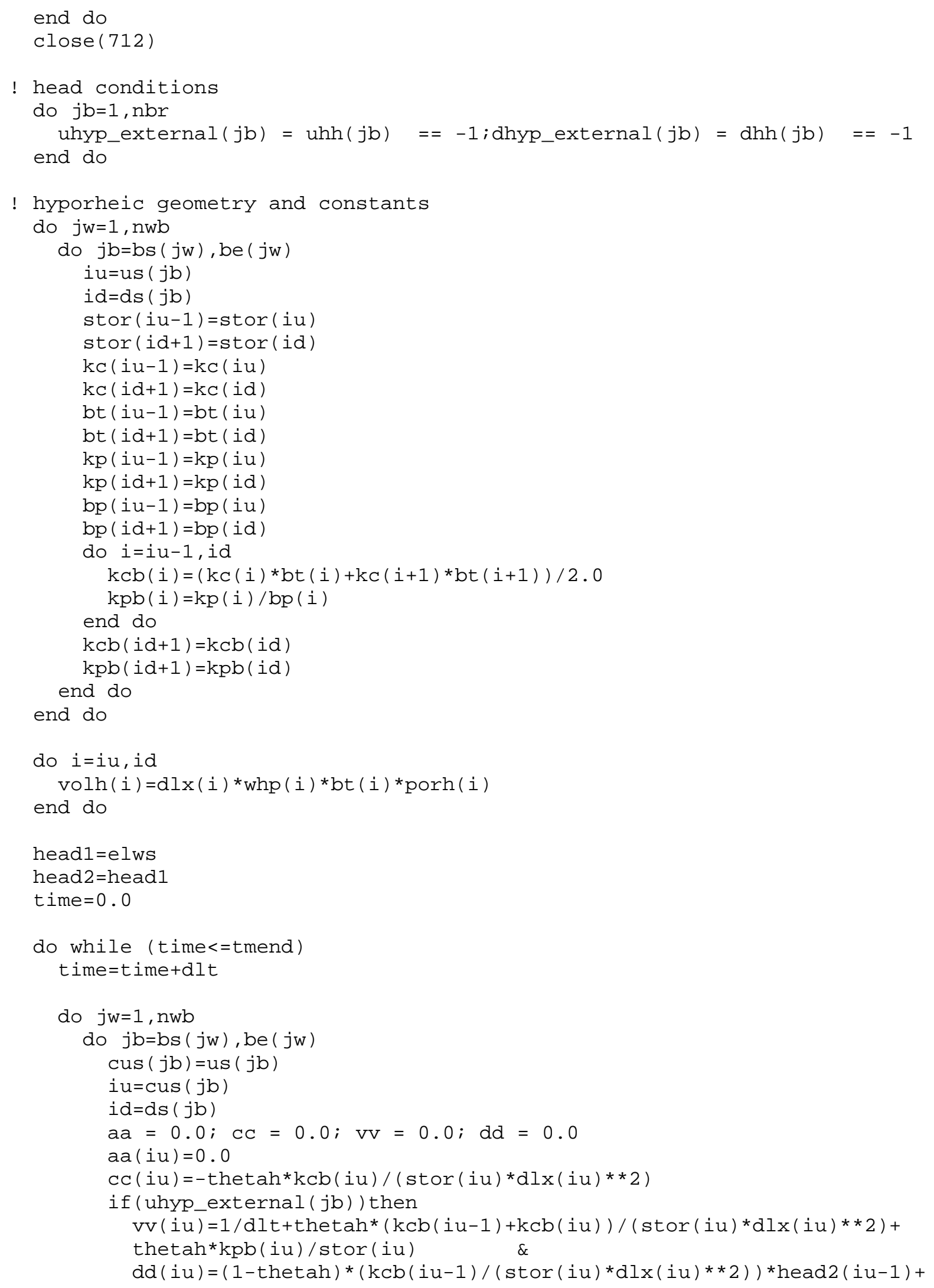


$(1 / \mathrm{dlt}-(1 . \odot-$ thetah $) * \mathrm{kpb}(\mathrm{iu}) / \mathrm{stor}(\mathrm{iu})-(1 . \odot-$

thetah $) *(k c b(i u)+k c b(i u-1)) / \&$

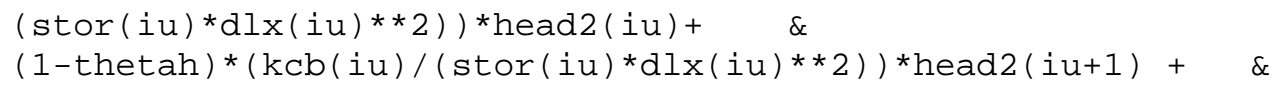

else $\mathrm{kpb}(i u) / \operatorname{stor}(i u) *$ elws $(i u)+\&$ thetah*kcb(iu-1)/(stor $\left.(i u){ }^{*} d l x(i u) * * 2\right) *$ head2(iu-1)

$v v(i u)=1 / d l t+$ thetah*kcb(iu)/(stor $(i d) * d l x(i d) * * 2)+$ thetah*kpb(iu)/stor (iu) $\mathrm{dd}(i u)=\left(1 / \mathrm{dlt}-(1.0-\right.$ thetah $){ }^{*} \mathrm{kpb}(i u) / \operatorname{stor}(i u)-(1.0-\text { thetah })^{*} \&$ $\mathrm{kcb}(i u) /(\operatorname{stor}(i u) * d l x(i u) * * 2)) *$ head2(iu) $\quad$ \&

$\&$

$(1-\operatorname{thetah}) *(\mathrm{kcb}(i u) /(\operatorname{stor}(i u) * \operatorname{dlx}(i u) * * 2)) *$ head $2(i u+1)$

end if $\mathrm{kpb}(i u) / \operatorname{stor}(i u){ }^{\star}$ elws $(i u)$

do $i=i u+1, i d-1$

aa $(i)=-$ thetah* $^{*} \mathrm{kcb}(i-1) /\left(\operatorname{stor}(i){ }^{*} \mathrm{dl} x(i) * * 2\right)$

$\operatorname{vv}(i)=1 / d l t+$ thetah* $(k c b(i-$

1) $+\mathrm{kcb}(i)) /\left(\operatorname{stor}(i){ }^{*} \mathrm{dl} \times(i){ }^{*} 2\right)+$ thetah $^{*} \mathrm{kpb}(i) / \operatorname{stor}(i)$ $c c(i)=-\operatorname{thetah}^{*} \mathrm{kcb}(i) /(\operatorname{stor}(i) * d l \times(i) * * 2)$

$d d(i)=(1-\operatorname{thetah}) *(k c b(i-1) /(\operatorname{stor}(i) * d l \times(i) * * 2)) *$ head2 $(i-1)$

$\&$

$\left(1 / \mathrm{dlt}-(1.0-\right.$ thetah $){ }^{*} \mathrm{kpb}(\mathrm{i}) / \operatorname{stor}(i)-(1.0-$ thetah $) *(\mathrm{kcb}(i)+$

$\&$

$\mathrm{kpb}(\mathrm{i}) / \operatorname{stor}(i){ }^{*} \operatorname{elws}(i)$

$\mathrm{kcb}(i-1)) /(\operatorname{stor}(i) * d l x(i) * * 2)) * \operatorname{head} 2(i)+\&$ $(1-$ thetah $) *(\operatorname{kcb}(i) /(\operatorname{stor}(i) * d l \times(i) * * 2)) *$ head $2(i+1)$

end do

$\operatorname{cc}($ id $)=\odot . \odot$

aa $($ id $)=-$ thetah ${ }^{*} \mathrm{kcb}($ id -1$) /($ stor $($ id $) * d l \times(i d) * * 2)$

if (dhyp_external $(j b))$ then $\operatorname{vv}($ id $)=1 / \mathrm{dlt}+$ thetah* $(\mathrm{kcb}$ (id -

1) $+\mathrm{kcb}($ id $)) /\left(\right.$ stor (id)* $\mathrm{dl} \times(\text { id })^{* * 2}$ ) +thetah*kpb(id)/stor (id)

$\&$ $\mathrm{dd}($ id $)=(1-$ thetah $) *(\operatorname{kcb}(i d-1) /(\operatorname{stor}($ id $) * d l x(i d) * * 2)) *$ head2 $($ id -1$)+$

$\&$ $\left(1 / \mathrm{dlt}-(1.0-\right.$ thetah $){ }^{*} \mathrm{kpb}(\mathrm{id}) / \mathrm{stor}(\mathrm{id})-(1.0-$ thetah $) *(\mathrm{kcb}(\mathrm{id}-1)+$

$\&$ $\mathrm{kcb}(\mathrm{id})) /(\operatorname{stor}($ id $) * \mathrm{dl} \times($ id $) * * 2)) *$ head2(id) $+\&$ $(1-$ thetah $) *(k c b(i d) /($ stor $(i d) * d l x(i d) * * 2)) *$ head2 $(i d+1)$

$\mathrm{kpb}(i d) / \operatorname{stor}(i d) * \operatorname{elws}(i d)+\&$

else thetah* $\mathrm{kcb}(\mathrm{id}) /(\operatorname{stor}($ id $) * \mathrm{dl} \times($ id $) * * 2) * \operatorname{head} 2(\mathrm{id}+1)$

$\operatorname{vv}($ id $)=1 / \mathrm{dl} t+\operatorname{thetah}^{*} \mathrm{kcb}(\mathrm{id}) /(\operatorname{stor}($ id $) * \mathrm{dl} l \times($ id $) * * 2)+\operatorname{thetah}^{*} \mathrm{kcb}(\mathrm{id}-1) /$

$\&$ (stor (id)*dlx(id)**2)+thetah*kpb(id)/stor (id) $\mathrm{dd}(i \mathrm{~d})=(1-$ thetah $) *(\operatorname{kcb}(i d-1) /(\operatorname{stor}(i d) * d l \times(i d) * * 2)) *$ head2 $(i d-1)+$

$\&$

$\left(1 / \mathrm{dlt}-(1.0-\right.$ thetah $){ }^{*} \mathrm{kpb}(\mathrm{id}) / \operatorname{stor}($ id $)-(1.0-$ thetah $){ }^{*} \mathrm{kcb}(\mathrm{id}-1) /$

$\&$

$$
(\operatorname{stor}(i d) * d l x(i d) * * 2)) * \text { head2(id) }+\&
$$

$(1-$ thetah $) *(k c b(i d) /(\text { stor }(i d) * d l x(i d) * * 2))^{*}$ head2 $(i d+1) \quad+$

$\mathrm{kpb}($ id)/stor (id)*elws (id)

end if

call tridiag (aa, vv, cc, dd, iu, id, imx, head1)

! calculating hyporheic velocity and flow rate between cells - assuming no flux boundaries at branch ends 


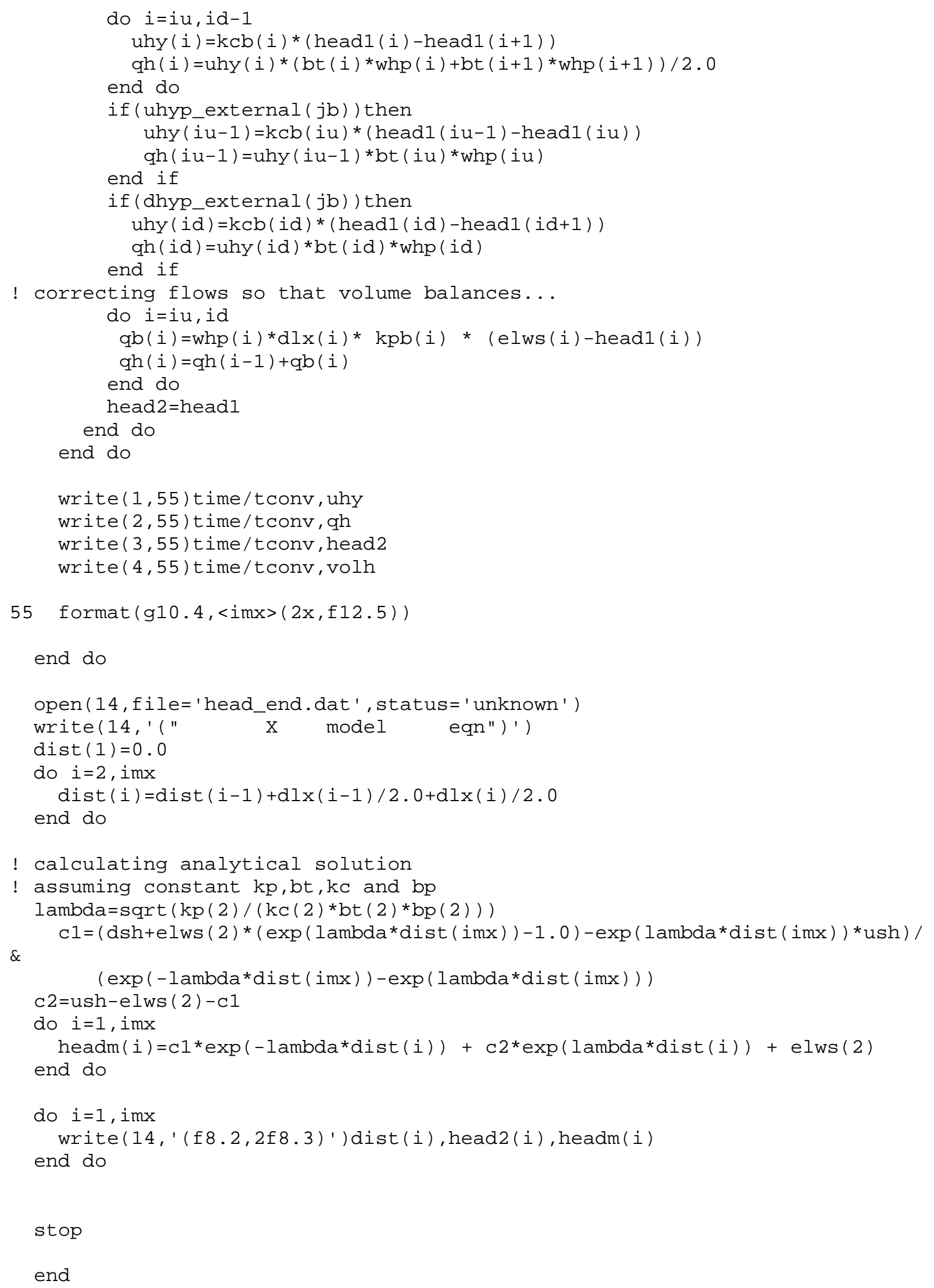




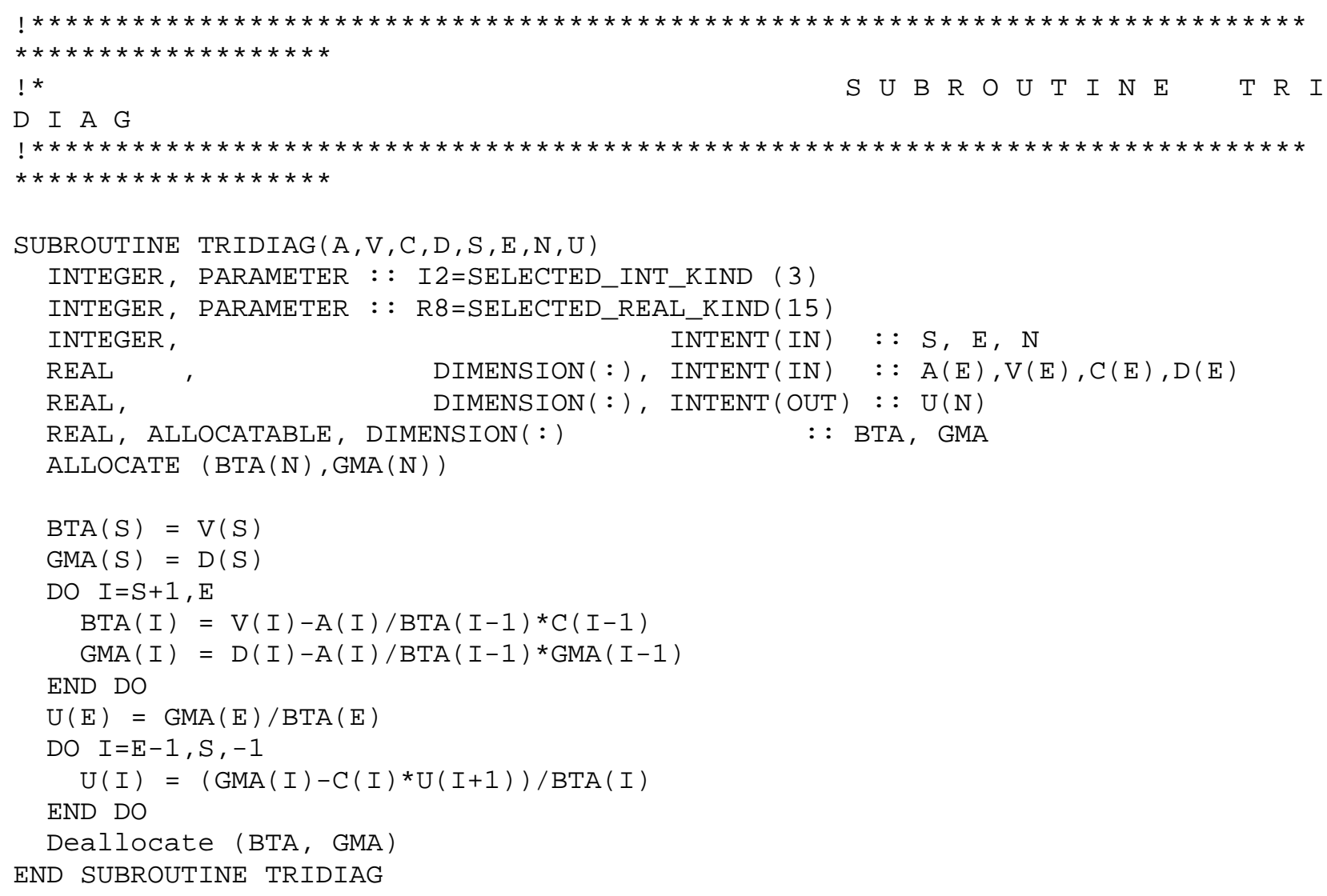

